\title{
GERAÇÃO DE ENERGIA (VAPOR) A PARTIR DA QUEIMA DE BIOMASSA (BAGAÇO DE CANA-DE-AÇÚCAR)
}

\author{
J. P. dos REIS ${ }^{1}$ e W. KLUCK ${ }^{1}$ \\ ${ }^{1}$ Católica de Santa Catarina em Jaraguá do Sul \\ E-mail para contato: jaissonreis@,catolicasc.org.br
}

RESUMO - A cana-de-açúcar é a principal fonte para produção do bioetanol e, graças ao solo fértil e clima propício para o plantio, o Brasil hoje é o maior produtor de cana-de-açúcar do mundo. $\mathrm{O}$ bagaço proveniente da moagem da cana era, tempos atrás, queimado apenas para redução de volume, no entanto, devido a avanços nas áreas de geração de energia através da queima de biomassas, acabou se tornando a principal fonte de energia dentro das indústrias sucroalcooleiras. O presente trabalho tem como objetivo principal avaliar a utilização do bagaço de cana-de-açúcar como fonte de energia térmica (vapor) em uma pequena indústria do ramo alimentício da região norte do estado de Santa Catarina, vislumbrado desde os processos produtivos da indústria até os equipamentos utilizados para a produção de energia. A caldeira estudada apresentou a eficiência térmica de 76,97\%, em condições normais de operação. Este valor é bastante alto comparado com os valores encontrados nas referências bibliográficas, possivelmente por divergência no valor de vazão mássica de vapor fornecido pelo fabricante/operador da caldeira comparado com o valor real. Por fim, apresentou-se um levantamento de custos comparando diferentes tipos de biomassas como combustíveis alternativos para o bagaço de cana-de-açúcar na caldeira, tendo em destaque a casca do arroz com um gasto mensal de $\mathrm{R} \$ 432,43$ por ser de fácil obtenção nas cooperativas agrícolas da região.

\section{INTRODUÇÃO}

Nos dias atuais, a utilização de biomassas para produção de energia é um recurso bastante amplo e variável. As biomassas são materiais constituídos principalmente de substâncias de origem orgânica, ou seja, animal ou vegetal. Algumas das vantagens desses recursos, além de uma menor agressividade ao meio ambiente, são o baixo custo de produção, a possibilidade de utilização dos resíduos e o fato de que algumas delas eram consideradas escória (como o bagaço da cana-de-açúcar e a casca de arroz, por exemplo, as quais eram anteriormente queimadas apenas para redução de seu volume) mesmo possuindo um poder calorífico considerável.

Estes exemplos de biomassas, antes da utilização para produção de energia, eram descartadas por não apresentarem uma opção de utilização rentável. Com as leis e punições cada vez mais severas sobre a degradação do meio ambiente, e, com o aperfeiçoamento das tecnologias e equipamentos para geração de energia, a utilização de biomassas como fontes de energia se tornou, além de útil para a compactação desses resíduos, uma opção viável, e até, em alguns casos, lucrativa. 
Os objetivos traçados para a realização do presente estudo foram, primeiramente elaborar um estudo de caso em uma pequena indústria de alimentos da região norte de Santa Catarina para avaliação da utilização de bagaço de cana-de-açúcar como combustível em uma caldeira para geração de energia, soma-se a este objetivo, calcular a eficiência térmica da caldeira utilizada para geração de vapor e comparar o bagaço de cana-de-açúcar com outras formas de biomassa para utilização como combustíveis na caldeira.

\section{FUNDAMENTAÇÃO TEÓRICA}

\subsection{Processo de geração de energia através da queima do bagaço e palha da cana-de- açúcar}

O processo de geração de energia dentro das plantas das usinas de açúcar e álcool é baseado nos processos de cogeração. Cogeração de energia é definida como a transformação de uma forma de energia em mais de uma forma de energia útil. Dentre as formas de energia úteis mais utilizadas estão a energia mecânica (movimentar máquinas, equipamentos e turbinas de geração de energia elétrica) e térmica (geração de vapor, frio ou calor).

O processo de cogeração apresenta uma eficiência energética mais alta, uma vez que não há desperdício de energia térmica como ocorre nas usinas termoelétricas, pois esta energia é utilizada em processos internos na usina como secagem, evaporação, aquecimento, cozimento e destilação (REVISTA GALILEU, 2013).

Basicamente, o bagaço de cana, após passar pelo processo de secagem, tendo ainda cerca de $50 \%$ de umidade, é utilizado como combustível para as fornalhas das caldeiras para evaporação da água e geração de vapor. $O$ vapor é então canalizado e utilizado em turbinas acopladas a geradores para a conversão de energia mecânica em energia elétrica. A energia térmica gerada nas caldeiras também é direcionada a trocadores de calor para utilização nos processos de fabricação do etanol. A maior parte da energia elétrica gerada é consumida nos processos internos da usina, sendo o sobressalente vendido às concessionárias locais (BASQUEROTTO, 2010).

\section{MATERIAIS E MÉTODOS}

Para um melhor entendimento do tema proposto, foi elaborado um estudo de caso em uma pequena indústria do ramo alimentício, localizada em Massaranduba/SC, a qual utiliza vapor d'água, produzido em uma caldeira que utiliza bagaço da cana-de-açúcar como combustível, em seu processo produtivo.

Para se conhecer o processo produtivo e também todo o processo de geração de energia através da queima do bagaço da cana-de-açúcar, foram realizadas algumas visitas à indústria para coleta de dados e entendimento do processo produtivo do melado de cana-deaçúcar. 
A cana-de-açúcar, é utilizada na indústria em estudo para a produção do melado, sendo que o resíduo da extração do caldo na moenda, bagaço da cana-de-açúcar, é utilizado para alimentação da caldeira para a geração de vapor para utilização nos processos produtivos. Além do melado, a empresa produz conservas de legumes e outros vegetais como palmeira real, beterraba, pepino, picles, cenoura, vagem, couve e cebola. O melado é produzido na indústria basicamente para a obtenção do bagaço da cana, não sendo o produto "carro chefe" da indústria. O melado nada mais é do que o caldo de cana concentrado pela evaporação da água até atingir um teor de sólido de $65^{\circ} \mathrm{BX}$ a $75^{\circ} \mathrm{BX}$.

\section{1 - Cálculo do poder calorífico do bagaço de cana-de-açucar}

Para determinação do poder calorífico inferior, PCI [J/kg], do bagaço da cana-deaçúcar, foi utilizado como base um artigo publicado por Anderson dos Santos Morais e Marcelo Bacci da Silva (2008) no XXVIII Encontro Nacional de Engenharia de Produção, onde os mesmos determinaram o poder calorífico superior, PCS [J/kg], do bagaço da cana-deaçúcar em função da umidade, $U$ [\%]. Após vários ensaios, Morais e Silva, chegaram aos resultados dispostos na Tabela 1.

Tabela 1 - Poder calorífico superior x umidade.

\begin{tabular}{c|c}
\hline Poder Calorífico Superior (J/kg) & Umidade (\%) \\
\hline 18.254 .450 & 0 \\
16.684 .400 & 10 \\
15.244 .140 & 20 \\
13.167 .490 & 30 \\
9.524 .970 & 50 \\
\hline
\end{tabular}

Fonte: Morais \& Silva, 2008, Adaptado.

\section{2 - Cálculo de eficiência térmica da caldeira}

Para fins de cálculo da eficiência térmica da caldeira, $\eta_{t}[-]$, conforme mostra a Equação 1, considerou-se o poder calorífico inferior do bagaço da cana-de-açúcar igual ao poder calorífico superior, pois não foram encontrados valores do mesmo nas referências bibliográficas pesquisadas.

$$
\eta_{t}=\frac{\dot{m}_{v}\left(h_{v \text { saída }}-h_{v \text { entrada }}\right)}{\dot{m}_{c} P C I}[-]
$$

Onde:

$\eta_{t}:$ Eficiência Térmica

$\dot{m}_{v}$ : Vazão Mássica de Vapor $(\mathrm{kg} / \mathrm{s})$

$\dot{m}_{c}$ : Vazão Mássica de Combustível $(\mathrm{kg} / \mathrm{s})$

PCI: Poder Calorífico Inferior $(\mathrm{J} / \mathrm{kg})$

$h_{v \text { saída: }}$ Entalpia Específica do Vapor na Saída $(\mathrm{J} / \mathrm{kg})$

$h_{\text {ventrada: }}$ Entalpia Específica do Vapor na Entrada $(\mathrm{J} / \mathrm{kg})$ 


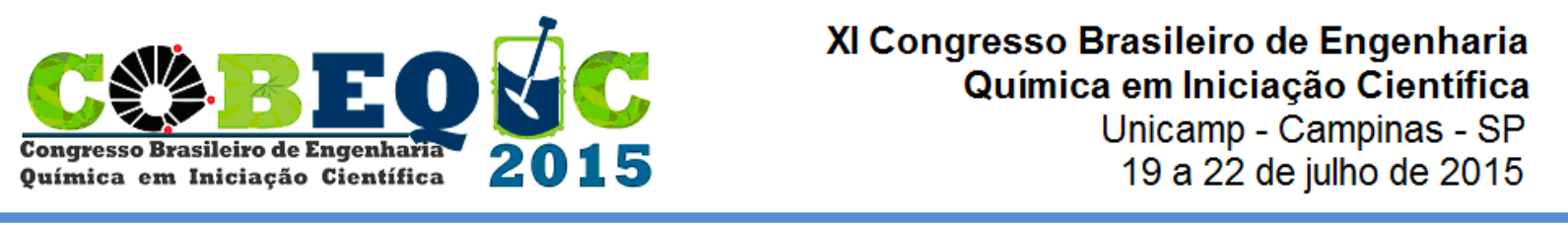

\section{RESULTADOS E DISCUSSÕES}

\subsection{Eficiência térmica da caldeira}

Com base nos dados termodinâmicos para o vapor de água, pode-se calcular a eficiência térmica da caldeira para condições normais de trabalho $\left(\dot{m}_{v}=400 \mathrm{~kg} / \mathrm{h}\right)$ :

$\eta_{t}=\frac{0,1111 \times(2.725 .300-105.132,5)}{0,0277 \times 13.653 .426}$

$\eta_{t}=0,7697[-]\left[\eta_{t}=76,97 \%\right.$

E para condições extremas $\left(\dot{m}_{v}=800 \mathrm{~kg} / \mathrm{h}\right)$ :

$\eta_{t}=\frac{0,2222 \times(2.763 .500-105.502,5)}{0,0694 \times 13.653 .426}$

$\eta_{t}=0,6233[-]$ 国 $\eta_{t}=62,33 \%$

Sabe-se que esta eficiência térmica é bastante inferior nos momentos iniciais de operação da caldeira, pois, pelo fato da mesma ser do tipo flamotubular antes de iniciar a produção de vapor toda a quantidade de água $(1.000 \mathrm{~L})$ contida dentro do corpo da caldeira deve ser aquecido, sendo necessária a queima de uma quantidade muito maior de combustível na fornalha.

\subsection{Bagaço de cana-de-açúcar $x$ Outras formas de biomassa}

Por fim, foi avaliada a utilização de outros tipos de biomassas para a produção de vapor. Como opções na região existem o cavaco de eucalipto, casca de arroz e madeira de pinus (lenha). Cada biomassa possui um poder calorífico inferior diferente, sendo estes dispostos na Tabela 2.

Tabela 2 - Poder calorífico inferior de diferentes biomassas.

\begin{tabular}{l|c}
\hline \multicolumn{1}{c}{ Biomassa } & Poder Calorífico Inferior (J/kg) \\
\hline Casca de Arroz & 13.816 .440 \\
Cavaco de Eucalipto & 18.003 .240 \\
Madeira de Pinus & 14.653 .800 \\
Bagaço de Cana & 13.653 .426 \\
\hline Fonte: Aalborg Industries, 2013, Adaptado.
\end{tabular}

Fonte: Aalborg Industries, 2013, Adaptado.

Considerando que a eficiência térmica da caldeira $(76,97 \%)$ permaneça a mesma para a utilização de outros tipos de biomassas e, a partir da equação da eficiência térmica vista anteriormente, pode-se determinar, para condições normais de geração de vapor $(400 \mathrm{~kg} / \mathrm{h})$, apenas rearranjando os termos da Equação 1, as quantidades de massas das biomassas mencionadas acima. Sabendo que a caldeira trabalha 4 horas por dia, 22 dias por mês, seriam consumidas, conforme Tabela 3, as seguintes quantidades de biomassas: 


\begin{tabular}{|c|c|c|c|c|}
\hline Biomassa & $\begin{array}{c}\text { Vazão Mássica } \\
(\mathrm{kg} / \mathrm{s})\end{array}$ & $\begin{array}{c}\text { Vazão Mássica } \\
(\mathbf{k g} / \mathbf{h})\end{array}$ & $\begin{array}{c}\text { Consumo Diário } \\
\text { (kg/dia) }\end{array}$ & $\begin{array}{c}\text { Consumo } \\
\text { Mensal (kg/mês) }\end{array}$ \\
\hline Casca de Arroz & 0,0273 & 98,28 & 393,12 & $8.648,64$ \\
\hline Cavaco de Eucalipto & 0,0210 & 75,60 & 302,40 & $6.652,80$ \\
\hline Madeira de Pinus & 0,0258 & 92,88 & 371,52 & $8.173,44$ \\
\hline Bagaço de Cana & 0,0277 & 100,00 & 400,00 & $8.800,00$ \\
\hline
\end{tabular}

E com base no custo por unidade de massa de cada biomassa, conforme fornecedores da região, tem-se o custo mensal de combustível, visto na Tabela 4, para produção da energia térmica. Vale ressaltar que como o bagaço já é proveniente da fabricação do melado, o mesmo não acarreta custo algum a sua obtenção. Além de que, na região, não há fornecedores para este tipo de biomassa.

Tabela 4 - Valor mensal gasto para diferentes biomassas em energia térmica.

\begin{tabular}{l|ccc}
\hline \multicolumn{1}{c|}{ Biomassa } & Valor Unitário (R\$/kg) & Valor Mensal (R\$/mês) \\
\hline Casca de Arroz & $\mathrm{R} \$ 0,02$ & $\mathrm{R} \$ 172,97$ \\
Cavaco de Eucalipto & $\mathrm{R} \$ 0,0714$ & $\mathrm{R} \$ 475,00$ \\
Madeira de Pinus & $\mathrm{R} \$ 0,1875$ & $\mathrm{R} \$ 1.532,52$ \\
Bagaço de Cana & $\mathrm{R} \$ 0,00$ & $\mathrm{R} \$ 0,00$ \\
\hline
\end{tabular}

Fonte: O Autor, 2013.

Além deste valor, como as demais biomassas devem ser transportadas da origem até o local de armazenamento na indústria, o deslocamento deve ser pago por conta do comprador, sendo este, para Jaraguá do Sul e região, de $\mathrm{R} \$ 0,03$ por quilograma de material transportado. Assim, o custo final mensal pode ser visto na Tabela 5.

Tabela 5 - Valor mensal gasto para diferentes biomassas em energia térmica (com frete).

\begin{tabular}{lc}
\hline \multicolumn{1}{c|}{ Biomassa } & Valor Mensal (R\$/mês) \\
\hline Casca de Arroz & $\mathrm{R} \$ 432,43$ \\
Cavaco de Eucalipto & $\mathrm{R} \$ 674,58$ \\
Madeira de Pinus & $\mathrm{R} \$ 1.777,72$ \\
Bagaço de Cana & $\mathrm{R} \$ 0,00$ \\
\hline
\end{tabular}

Fonte: O Autor, 2013.

Comparando o bagaço de cana-de-açúcar, como combustível, com as demais biomassas, este se coloca como principal opção para a indústria em estudo, uma vez que seu custo de produção é nulo, trazendo ainda lucro durante sua obtenção com a produção e venda do melado.

Como segunda opção, caso haja algum problema nos equipamentos utilizados para produção do melado ou mesmo pela falta de produção devido a escassez de procura no mercado, tem-se a casca de arroz como opção viável, a qual é abundante dentro do município de Massaranduba.

A casca de arroz apresenta um poder calorífico inferior levemente superior ao bagaço da cana, sendo a quantidade de biomassa consumida mensalmente levemente inferior. Devido 
a grande produção de arroz no município de Massaranduba, a casca, que não é utilizada dentro das caldeiras das próprias indústrias de processamento de arroz, é vendida a um preço bastante baixo e acessível.

Por ser um material a granel, seu armazenamento e inserção para dentro da fornalha seria um pouco mais complexo que do bagaço. Seria necessário um local mais reservado (fechado nas laterais, por exemplo) para armazenamento, a fim de evitar o escoamento da mesma devido a fortes ventos ou chuvas. Para abastecimento da fornalha, a utilização de um sistema de bomba de fuso ou de um reservatório acima desta seria ideal para agilizar o processo, além de, dentro da fornalha, ser essencial a utilização de uma grade ao fundo mais fechada para evitar a perda de combustível, que não foi incinerado, por debaixo dos tubos onde escoam as cinzas para fora da fornalha.

O cavaco de eucalipto, apesar de ser um pouco mais caro ( $\mathrm{R} \$ 242,15$ por mês a mais que a casca de arroz), ainda se torna uma opção viável para abastecimento da fornalha, porém, as mesmas modificações consideradas para a queima da casca de arroz devem ser feitas para esta biomassa, pois também é fornecida a granel.

Caso opte-se pela utilização do cavaco de eucalipto, sua umidade deve ser controlada, pois se este ficar com um nível de umidade muito alto, dificultará a queima e se perderá muita energia térmica para efetua-la.

A madeira de pinus, apesar de ser relativamente barata em comparação com o eucalipto (caso o eucalipto fosse fornecido na forma de lenha), torna-se inviável, pois sua utilização acarretaria em um gasto com combustível 2,63 vezes maior em comparação com o cavaco de eucalipto e 4,11 vezes maior em comparação com a casca de arroz, conforme visualizado na Tabela 6 .

Tabela 6 - Comparativo de custos entre as biomassas.

\begin{tabular}{l|c|c|c}
\hline \multicolumn{1}{c|}{ Biomassa } & Valor Mensal (R\$/mês) & $\begin{array}{c}\text { "X" Vezes Mais Caro } \\
\text { Que Casca de Arroz }\end{array}$ & $\begin{array}{c}\text { “' Vezes Mais Caro } \\
\text { Que Cavaco de } \\
\text { Eucalipto }\end{array}$ \\
\hline Casca de Arroz & $\mathrm{R} \$ 432,43$ & $\mathrm{X}$ & $\mathrm{X}$ \\
Cavaco de Eucalipto & $\mathrm{R} \$ 674,58$ & 1,56 & $\mathrm{X}$ \\
Madeira de Pinus & $\mathrm{R} \$ 1.777,72$ & 4,11 & 2,63 \\
\hline
\end{tabular}

Apesar disso, possui uma facilidade maior em se armazenar e inserir dentro da fornalha que as outras biomassas, não necessitando de qualquer modificação no depósito ou na fornalha existente.

\section{CONSIDERAÇÕES FINAIS}

A utilização do bagaço de cana-de-açúcar como combustível para geração de energia é algo bastante comum para as indústrias do setor sucroalcooleiro, as quais tem este como subproduto da produção de bioetanol e açúcar. Esta biomassa possui um poder calorífico considerável, além de ser de fácil manuseio e relativamente barata se comparada com outros 


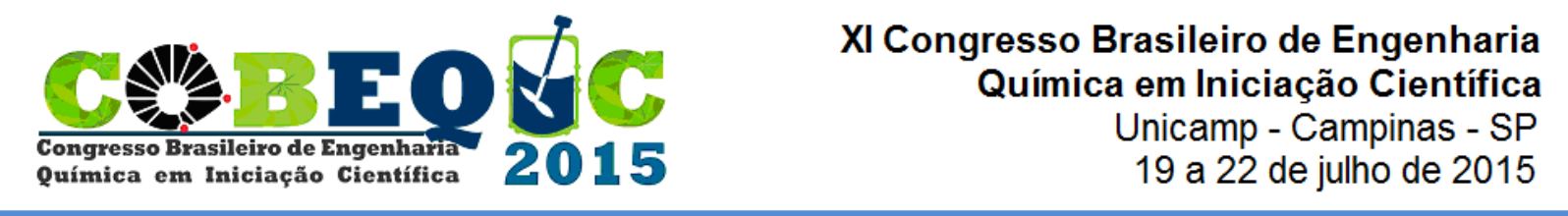

tipos de biomassas mais comuns como madeira (na forma de serragem, cavaco ou lenha) e casca de arroz.

Na comparação entre os custos gerados com a utilização do bagaço de cana-de-açúcar em relação a outras biomassas (casca de arroz, cavaco de eucalipto e madeira de pinus lenha), o bagaço sempre será a primeira opção para a indústria estudada, pois seu custo de produção/aquisição é zero. O bagaço é subproduto da produção de melado, que por sua vez é vendido a fim de obter-se lucro. Ou seja, não há custo algum de produção/aquisição do bagaço, sendo o custo do processamento já incluso no preço final do melado.

Caso haja algum problema na produção do melado e consequentemente na produção de bagaço por falta de matéria-prima ou procura do mercado, a casca de arroz, produzida na cidade de Massaranduba, se coloca como substituto viável por possuir um custo de aquisição baixo apesar das dificuldades de armazenamento, pois é um material relativamente leve e que pode ser levado com as forças dos ventos, e de inserção para dentro da fornalha, pois como é a granel há a necessidade de utilização de um reservatório acima da fornalha ou o auxílio de uma bomba de fuso. O cavaco de eucalipto apresenta as mesmas dificuldades que a casca de arroz, porém, com um custo de aquisição um pouco maior. Já a lenha, torna-se inviável tendo em vista seu valor de mercado muito mais caro.

A utilização de biomassas vem se tornando uma tendência com o intuito de se ter um mundo mais limpo e sustentável. Cada vez mais as empresas sustentáveis, ou seja, que se comprometam com o meio ambiente, vem sendo observadas com melhores olhos por fornecedores e clientes garantindo sua permanência e crescimento no mercado competitivo atual.

\section{REFERÊNCIAS}

BASQUEROTTO, Cláudio Henrique Cequeira Costa. Cogeração de energia elétrica com bagaço de cana-de-açúcar compressado (briquete). 2010. 55 f. Trabalho de Conclusão de Curso - Faculdade de Tecnologia de Araçatuba, Araçatuba, 2010.

MORAIS, Anderson dos Santos; SILVA, Marcelo Bacci da. Avaliação energética do bagaço de cana em diferentes níveis de umidade e graus de compactação. 2008. Enegep, Rio de Janeiro, 2008.

REVISTA GALILEU. Participação de usinas de cana na geração de energia do país poderia ser seis vezes maior. 2013. Disponível em:

$<$ http://revistagalileu.globo.com/Revista/Common/0,,EMI326727-18537,00-

PARTICIPACAO+DE+USINAS+DE+CANA+NA+GERACAO+DE+ENERGIA+DO+PAIS +PODERIA+SER+SE.html>. Acesso em: 20 mar. 2013. 